\title{
Nuevas y antiguas identidades regionales: conflicto, exclusión e hibridaje. El caso de la región del Maule
}

Francisco Letelier. Universidad Católica del Maule. Talca, Chile. Claudia Concha. Universidad Católica del Maule. Talca, Chile.

RESUMEN | A partir del caso de la región del Maule en Chile se reflexiona acerca de los procesos de construcción de región. Utilizando las categorías de antiguas y nuevas regiones e identidades funcionales y profundas (Paasi, 2011; Terlouw, 2011), se revisan los efectos territoriales que tuvo el proceso de regionalización chileno iniciado en los años setenta. Utilizando diversas fuentes de información, se ponen en evidencia las desigualdades que el proceso de regionalización produjo en el territorio, proceso conceptualizado -en el caso del Maule- como de constitución de la región nueva, asentada en torno a las dos ciudades más importantes del territorio así definido; y precarización de la región antigua, representada por las antiguas provincias. La primera se consolida en desmedro de la segunda. Pese a estas diferencias, se constata, al mismo tiempo, las hibridaciones: la región nueva contiene a la región antigua, y viceversa. Se concluye que articular esta dicotomía es central para los procesos de desarrollo regional.

PALABRAS CLAVE | desarrollo regional y local, desigualdades regionales, descentralización.

ABSTRACT | This article reflects on the processes of region building, considering the case of the Maule region in Chile. Drawing upon the categories of old and new regions, as well as functional and deep identities (Passi, 2011; Terlouw, 2011), the territorial effects related to the Chilean process of regionalization, started in the 1970s are reviewed. Using different sources of information, the inequalities generated in the territory by this process are shown, conceptualized as the constitution of the new region, based in the two main cities of the region; and the precarization of the old region, represented by the old provinces. The first region is developed at the expense of the second one. Despite these differences, two hybridations are observed; the new region includes the old one, and vice versa. It is concluded that the management of this dichotomy is key to the processes of regional development.

KEY WORDS | regional and local development, territorial inequalities, descentralization. 


\section{Introducción}

En Chile, la regionalización es un proceso impulsado y comandado desde el poder central (Boisier, 2000; Valenzuela, 1999). Iniciada en 1974, tuvo dos motivaciones principales: i) en el ámbito político-económico, buscó mejorar la efectividad del gasto, desconcentrar servicios para aumentar la eficiencia del sector privado volcado a los mercados internacionales, y disminuir el tamaño del Estado central (Valenzuela, 1999); ii) en lo geopolítico, obedeció a la búsqueda de una estructura de control para ejercer gobierno y resguardar la seguridad nacional (Arenas, Hidalgo, Orellana \& Aliaga, 2007).

Boisier (2000) indica que la regionalización chilena no responde a demandas sociales o circunstancias históricas. En términos de la teoría de las políticas públicas, ella es el resultado de una racionalidad burocrática weberiana. La regionalización nace desde el corazón del Estado y es impuesta, primero, por un decreto presidencial; y posteriormente, con la fuerza de un decreto ley en plena vigencia de un autoritarismo a ultranza.

La delimitación de las actuales regiones no tuvo un correlato en las características agroecológicas, históricas o económico-productivas del territorio. Más que reconocer la existencia de una configuración territorial preexistente, buscó establecer regiones que fuesen funcionales al proyecto de transformaciones neoliberales iniciado por el gobierno militar (Arenas et al., 2007, p. 361). Al respecto, Milton Santos (1997), al referirse al espacio geográfico contemporáneo, señala que este es cada vez más artificial, que su valor depende de su eficiencia y contribución a la productividad económica, y que esto produce espacios hegemónicos y homogéneos. Como indica Giddens (1984), se generan divisiones espaciotemporales de actividades y de relación, a las cuales de denomina "regiones".

Para Soja (1989), la noción de región se basa en la geografía del poder, que segrega y compartimenta la interacción humana, puesto que controla la presencia y la ausencia, la inclusión y la exclusión. Complementando estas ideas, Paasi (2011) y Terlouw (2011) argumentan que las regiones son estructuras y procesos institucionales que existen y obtienen sus significados en la práctica social y en una constelación de relaciones de poder (Allen, Massey \& Cochrane, 1998, citado en Paasi, 2011). Estas, las relaciones de poder, pueden tener su origen en complejos contextos institucionales localizados en las propias regiones, o fuera de ellas (Paasi, 2011), como ocurre en el caso chileno.

Para Paasi y Terlouw, tres son los aspectos del proceso de constitución de una región. En primer lugar, la forma territorial, vinculada a su fisonomía física, sus bordes históricos y las características de su población. Para el caso chileno, las actuales regiones se conformaron sin considerar, por ejemplo, las relaciones sociales, productivas, culturales- existentes entre territorios, los que hoy son partes constitutivas de regiones distintas ${ }^{1}$, así como tampoco dan cuenta de dinámicas

$1 \longdiv { \text { La provincia de Cauquenes en el Maule con la zona costera de la provincia de Nuble en Biobío y la parte } }$ sur de la provincia de Curicó en el Maule con la provincia de Colchagua en la región de O’Higgins. 
interregionales que fueron afectadas por la nueva división provincial ${ }^{2}$. Un segundo aspecto hace referencia al universo simbólico que se conforma y que se manifiesta en la práctica social que produce y reproduce la región, y que permite construir narrativas de identidad para simbolizarla (Giménez, 1994). Diversos estudios (Barómetro Regional, 2013; Encuesta Nacional de Estratificación Social, 2009) muestran la escasa identificación de las personas con lo regional, situación que cambia cuando se habla de lo local-comunal. La propia Subsecretaría de Desarrollo Regional (Subdere, 2009) reconoce que el gran déficit del proceso de descentralización en Chile se da en el ámbito de la conformación de identidades regionales.

Finalmente está la forma institucional, que se manifiesta como representaciones políticas, prácticas de planificación, gobernanza y políticas locales, sistemas de educación, las asociaciones que funcionan en la sociedad civil, medios regionales y locales, y literatura (Paasi, 2011; Terlouw, 2011). En esta doble dimensión de constitución de Estado y sociedad civil regional, vemos que los avances son escasos. Por ejemplo, en el ámbito de las representaciones políticas, los delegados regionales (consejeros) tradicionalmente han sido nominados indirectamente, cuestión que si bien cambió en la elección de noviembre de 2013, dejó a los consejeros elegidos con atribuciones limitadas respecto a las del jefe del gobierno regional (intendente) quien es designado por el o la Presidenta de la República, ante quien responde (Altman, 2011).

A lo anterior se ańade que los niveles de conocimiento de los ciudadanos respecto a los estamentos regionales y provinciales de gobierno, como el grado de la confianza en ellos, son reducidos (Encuesta Nacional de Estratificación Social [ENE], 2009; Barómetro Regional, 2013, entre otros). Respecto a las prácticas de planificación y gobernanza, pese a la puesta en marcha de la Ley Orgánica de Administración y Gobiernos Regionales - que ha permitido incrementar el nivel de incidencia regional sobre la inversión pública, que hoy llega a cerca de un $20 \%$, así como dotar a las regiones de un pequeño aparato burocrático-, la planificación que se diseña en el nivel de las regiones es solo indicativa (Estrategias de Desarrollo Regional y anteproyecto regional de inversiones) y poco tiene que ver con la inversión realizada. De hecho, no existen procesos de planificación regional, ni políticas regionales reales (Espinoza \& Rabi-Blondel, 2013).

Como resultado de estas limitaciones, la región aparece más como una delegación política del gobierno central, que como un espacio de representación de los ciudadanos. En el ámbito de la sociedad civil encontramos una incipiente y muy limitada articulación de actores a escala regional (Universidad de los Lagos, 2010). Diversos estudios muestran que si bien el tejido asociativo chileno tiene densidad, la vinculación de cada unidad con otros grupos no se manifiesta en la participación en estructuras, movimientos o corrientes asociativas de alcance provincial o regional, desde las cuales se dinamice la sociedad y se elabore una crítica reformista y cultural, se generen alternativas, se produzcan y administren discursos y se construya capital cultural (Programa de Naciones Unidas para el Desarrollo [PNUD], 2000).

El caso más notable es la separación de la antigua provincia de Maule, que llevó Constitución a la provincia de Talca. 
Con todo, lo que denominamos "región" y naturalizamos como una entidad territorial realmente existente, es hoy más un dispositivo político-administrativo que el Estado central ha impuesto sobre realidades territoriales, simbólicas e institucionales preexistentes: las antiguas provincias, departamentos y comunas, donde se encuentra la mayor densidad simbólica e institucional (Subdere, 2010) y donde el sentimiento de pertenencia se ha venido construyendo a través de narrativas variadas, como las relaciones entre los sujetos y la naturaleza, el paisaje, el medioambiente construido, la cultura, la etnicidad, la historia compartida, utopías, patrimonio tangible e intangible, entre otros (Méndez, 2007). No queremos decir con esto que la centralización comienza con la regionalización definida por la dictadura, sino que el alegato descentralizador, que ha estado presente sistemáticamente a lo largo de la historia de Chile (Valenzuela, 1999), quedó preso de una simulación llamada "región", que en vez de ser un espacio de representación política del territorio se convirtió en un locus de control del Estado nacional. De hecho, la Subdere (2010) habla de la necesidad de iniciar una segunda etapa asociada al desarrollo territorial subnacional, con foco en las condiciones y capacidades endógenas de regiones y comunas. Las estructuras de gobierno descentralizadas solo operan adecuadamente cuando tienen lugar procesos de desarrollo endógenos, liderados y conducidos por actores regionales, en función de sus prioridades y proyectos de desarrollo y en respuesta a su identidad y proyección (Subdere, 2009).

Reconociendo la debilidad en la constitución de identidades y actores regionales, estatales o de la sociedad civil capaces de demandar un proceso "desde adentro" (Subdere, 2009), las acciones de los gobiernos han profundizado los procesos de concentración de poder en nodos regionales ligados a la dimensión político-administrativa. Como resultado, los territorios subregionales preexistentes al proceso de regionalización, portadores de un sentido de pertenencia (Bengoa, 2008) y capital social y donde históricamente más se ha ejercitado la democracia local (Valenzuela, 1999), tienden a debilitarse. Las razones tienen su raíz en la superposición de dos capas de sentido en un mismo territorio: una constituida por la región oficial; la otra, aquella de la región histórica, simbólica e institucional. Nuestra hipótesis es que la construcción de región no se juega solo en la relación región-país, sino en la capacidad de generar vínculos entre el dispositivo político-administrativo que se ha venido instalando y consolidando en los últimos cuarenta ańos, al que llamamos región, y la realidad simbólica e institucional de los territorios preexistentes.

\section{Antiguas y nuevas regiones, identidades profundas y superficiales}

La doble constitución del territorio será analizada desde las categorías de Paasi (2011) y Terlouw (2011), que establecen, respectivamente, antiguas y nuevas regiones, e identidades funcionales y profundas. Pese a que su propuesta no utiliza la denominación "local", identificaremos las "antiguas regiones" y las "identidades profundas", con aquellos territorios y relatos subregionales y preexistentes a la conformación de la actual región político-administrativa. Al mismo tiempo, vinculamos las nociones de "región nueva" e "identidades superficiales" a los procesos de constitución de región de los últimos cuarenta años. 
Según Paasi (2011), las antiguas regiones han llegado a ser institucionalizadas como parte de un proceso de división social y espacial del trabajo, y son a menudo partes establecidas del sistema regional y de la conciencia social. En algunos casos, incluso las aspiraciones regionalistas de los grupos son una cuestión crucial. Estas regiones pueden ser movilizadoras de significantes sociales, historia, memoria y emociones. Su identidad puede ser decisiva para el desarrollo de prácticas de resistencia, a partir de las cuales los actores se oponen a la realidad de las redes globales del capitalismo financiero y sus impactos. Tales resistencias, señala el autor, también pueden emerger, por ejemplo, desde ecologismos radicales.

Las identidades profundas están más basadas en una cultura común y en relaciones comunitarias. Consideran aspectos normativos, están arraigadas y tienen raíces históricas. Valoran la región como un objetivo político en sí mismo y son integradoras: tienden a balancear los distintos intereses de los habitantes e integran diferentes políticas de un territorio (Terlouw, 2011).

Las nuevas regiones son prácticas y utilitarias (Shelby, 2005; citado en Terlouw, 2011). Típicamente son construidas ad hoc para proyectos que aspiran a desarrollar o incrementar la competitividad de tales unidades territoriales (Deas \& Lord, 2006; citados en Paasi, 2011). Nacen a menudo de procesos o proyectos de regionalización políticos y/o económicos. Sus identidades son fluidas y basadas en el diálogo y están vinculadas a un problema específico, que requiere menor vínculo entre individuos. Son mapas funcionales, relacionados con políticas sectoriales e intereses especiales; $y$, a diferencia de las identidades profundas, que cubren un amplio rango de características -culturales, sociales, políticas, medioambientales y económicas-, ponen el foco en pocos aspectos del territorio (mayoritariamente económicos).

En la conceptualización de Paasi (2011) y Terlouw (2011), se sitúa la región político-administrativa como una "región nueva", con una "identidad superficial", en tanto lo local es asimilado al concepto de "región antigua", portadora de "identidades profundas", noción que concibe el territorio desde una perspectiva cultural (Cuervo, 2006), en tanto entidad portadora de una memoria que aloja un pasado histórico de relaciones y conflictos. En último término, reconoce la existencia mental de tal región a través de las múltiples representaciones y significados que las personas elaboran respecto de los puntos, recorridos y áreas que habitan, y de los valores que les asignan.

Dicho lo anterior, el territorio surge como espacio de representaciones sociales (Moscovici, 1985; Jodelet, 1986) que integra lo estructural y lo individual. Ambas dimensiones se relacionan de forma dialéctica. Como indica Banchs (2000), el individuo se constituye y constituye sus representaciones; también constituye su mundo social, y construye y reconstruye permanentemente su propia realidad social y su propia identidad personal.

La noción de representación social permite acceder a los procesos de configuración y transformación del territorio. Para García (2006), el territorio como concepto abarca la dimensión del poder, en cuanto implica las prácticas de control y dominio sobre el espacio y una condición de circunscripción territorial que la expresa o simboliza; al mismo tiempo, el territorio es definido en función de lo que colectivamente se consideran las vivencias, nociones y valoraciones compartidas y 
a él ligadas; desde esta perspectiva, el territorio implica una delimitación simbólica que establece los adentros y los afueras en los sentidos de identificación de las gentes (pp. 78-79).

A esta concepción del territorio se añaden las vivencias, nociones y valoraciones compartidas y ligadas a él. El territorio como representación social solo es pensable y comprensible en la medida en que se conozcan y descifren los contenidos y las maneras como los sujetos viven, experimentan, imaginan, proyectan e inscriben en él sus sentimientos de pertenencia, sus intereses, sus prácticas y poderes.

El territorio en cuanto espacio de representaciones sociales es también expresión de identidades y afectos, intereses y proyectos diferenciados, encarnando así la complejidad de las relaciones que definen la vida social. Desde esta perspectiva, comprender y explicar la identidad que asume un grupo en un momento histórico dado, solo es posible en el marco de su interacción con otro (Banchs, 2000). Como resultado, la identidad de un grupo, si bien contiene un núcleo estable y compartido por sus miembros, también posee elementos cambiantes y plurales, lo que añade complejidad a su constitución.

A esta noción del territorio como espacio de representaciones sociales se agrega el carácter político de la representación social, en cuanto paradigma dominante que implica la imposición de una visión de mundo sobre otra; y finalmente su eficacia simbólica, es decir, el poder que tienen las representaciones sociales "de volver realidad lo que afirman” (García, 2006, p. 80).

Ahora bien, la superposición y traslape de la antigua región y de la nueva permiten observar la convivencia de dos formas opuestas de representaciones sociales en un mismo espacio, construcciones que expresan la complejidad del mundo de las identidades, las formas en que actores y grupos sociales se apropian y significan el territorio, y las tensiones y convergencias que en ese proceso se producen con las que maneja el Estado (García, 2006).

\section{Metodología}

Para observar los procesos de conflicto, exclusión e hibridaje que se han producido en el curso de la constitución de una nueva región (la región político-administrativa del Maule) y, por ende, el de transformación y debilitamiento de las regiones antiguas (provincias y comunas), se utiliza una aproximación que combina el análisis histórico, el socioespacial y el comprensivo. En primer lugar se hizo una breve reconstrucción de las implicancias que tienen para el territorio las transformaciones políticas y económicas implementadas desde 1974, destacando la instalación de un nuevo locus de control en el territorio: la zona Talca y Curicó. Así, hemos establecido que la región nueva, más que una nueva delimitación geográfica, es un dispositivo político localizado en la zona de influencia de las dos ciudades principales de la región. En segundo lugar se espacializó variables de infraestructura y productivas, evidenciando su concentración en ciertas zonas del territorio. En tercer lugar, se reconstruyó la trayectoria demográfica del territorio, mostrando cómo un fuerte y homogéneo proceso de urbanización, que comenzó a mediados de 1970, generó concentración de la población en la zona Talca-Curicó. Al mismo tiempo, se da 
cuenta de procesos de concentración política, demográfica y económica en ciertos territorios, a través del análisis de las ventas de empresas por comuna. Finalmente se incorporan datos de la encuesta regional de identidad ${ }^{3}$, que permitió acceder a las representaciones sociales en distintas escalas territoriales. Este análisis se complementó con el resultados de cincuenta entrevistas semiestructuradas y treinta biográficas a actores diversos: trabajadores, dirigentes sociales, jóvenes, elite política y elite económica. En esta última etapa se buscó contrastar las transformaciones espaciales y económicas, con las subjetividades que los propios sujetos han construido respecto de los procesos de transformación del territorio.

\section{Resultados}

\section{La constitución de la polaridad entre la región nueva y la región antigua en el Maule}

La regionalización produjo en el Maule tres efectos político territoriales: i) estableció una barrera administrativa y simbólica entre los flujos que se producían en los extremos norte y sur del territorio con las áreas vecinas, dificultando alianzas territoriales con zonas homogéneas fuera de la región y "obligando" a las localidades a mirar al centro de la "nueva región"; ii) eliminó los antiguos departamentos que, agrupando comunas, generaban una escala política más propicia para dialogar con las antiguas provincias; de hecho, hasta hoy la asociatividad comunal es un tema pendiente en la región; iii) la regionalización del Maule mantuvo las provincias más o menos con sus antiguos límites, pero las vació de poder, puso por encima de ellas una nueva estructura administrativa: la región, Talca como su capital, dándole a Curicó un rol central en la organización productiva del modelo agroexportador emergente.

Hasta principios de los ańos setenta, el modelo desarrollista produjo una fuerte urbanización en el Maule. Así, de 1952 a 1970, el incremento de la población urbana fue de 58,7\%. En los últimos cuarenta años, con la instalación de la "región nueva", la población siguió urbanizándose, pero se concentró en ciertos territorios, particularmente en el eje del Valle Central, dándoles a las ciudades intermedias regionales, Talca y Curicó, un rol central en el nuevo modelo económico neoliberal instalado en el país. Esto es coherente con varios estudios realizados sobre ciudades intermedias en Chile, los que coinciden en la importancia de estas ciudades como centros administrativos regionales y provinciales, centros prestadores de servicios para sus hinterlands, y centros de transformación industrial de recursos naturales (Mertins, 2000; Romero, Toledo \& Órdenes, 2001; Rovira, 2000). En los últimos cuarenta años, estas ciudades han despegado económicamente debido a su localización, convirtiéndose en unidades espacio-funcionales que atraen inversiones orientadas al mercado internacional -principalmente forestales, pesca, cultivos acuícolas y turismo especializado-, constituyéndose en verdaderos nodos en el sistema territorial chileno.

3 Encuesta Regional de Identidad: muestra aleatoria simple, en Ciudades Intermedias Mayores (сіM) con más de 100.000 habitantes; en Ciudades Intermedias Menores (CIME) con más de 10.000 habitantes; y en Pueblos de más de 1.000 habitantes. Los casos son 1.152 (384 por cada categoría de centro poblado) y tiene 5\% de error. Proyecto "Identidades e identidad en el Maule: Claves para imaginar el desarrollo regional en el Maule". 
La gravitación de Talca y Curicó se aceleró producto de la expansión de la actividad terciaria de comercio -transporte y servicios especializados-, la que, junto a la construcción de viviendas, adquirió un fuerte dinamismo durante estos años, incluso compensando el impulso de las actividades exportadoras (García-Huidobro \& Maragaño, 2010).

Desde la nueva región se implementaron las políticas de liberalización de los mercados y el desarrollo de una economía exportadora, impulsando la actividad agroindustrial y la industria vitivinícola, concentradas ambas en el Valle Central y particularmente en torno a las ciudades mayores, Talca y Curicó. Según la "Actualización del catastro de la agroindustria hortofrutícola chilena" (2012), la industria agrícola de la región del Maule cuenta con 55 plantas procesadoras de frutas y hortalizas, incluyendo 20 de congelados, 12 de conservas, 8 de aceites, 8 de deshidratados y 7 de jugos. Como se aprecia en la figura 1, la agroindustria se concentra en cantidad y variedad en el Valle Central, particularmente en la zona norte en la comuna de Teno; y en la zona oeste de las comunas de Romeral y de Curicó; y noreste de Molina.

FIGURA 1 | Región del Maule: localización de la agroindustria hortofrutícola, 2012

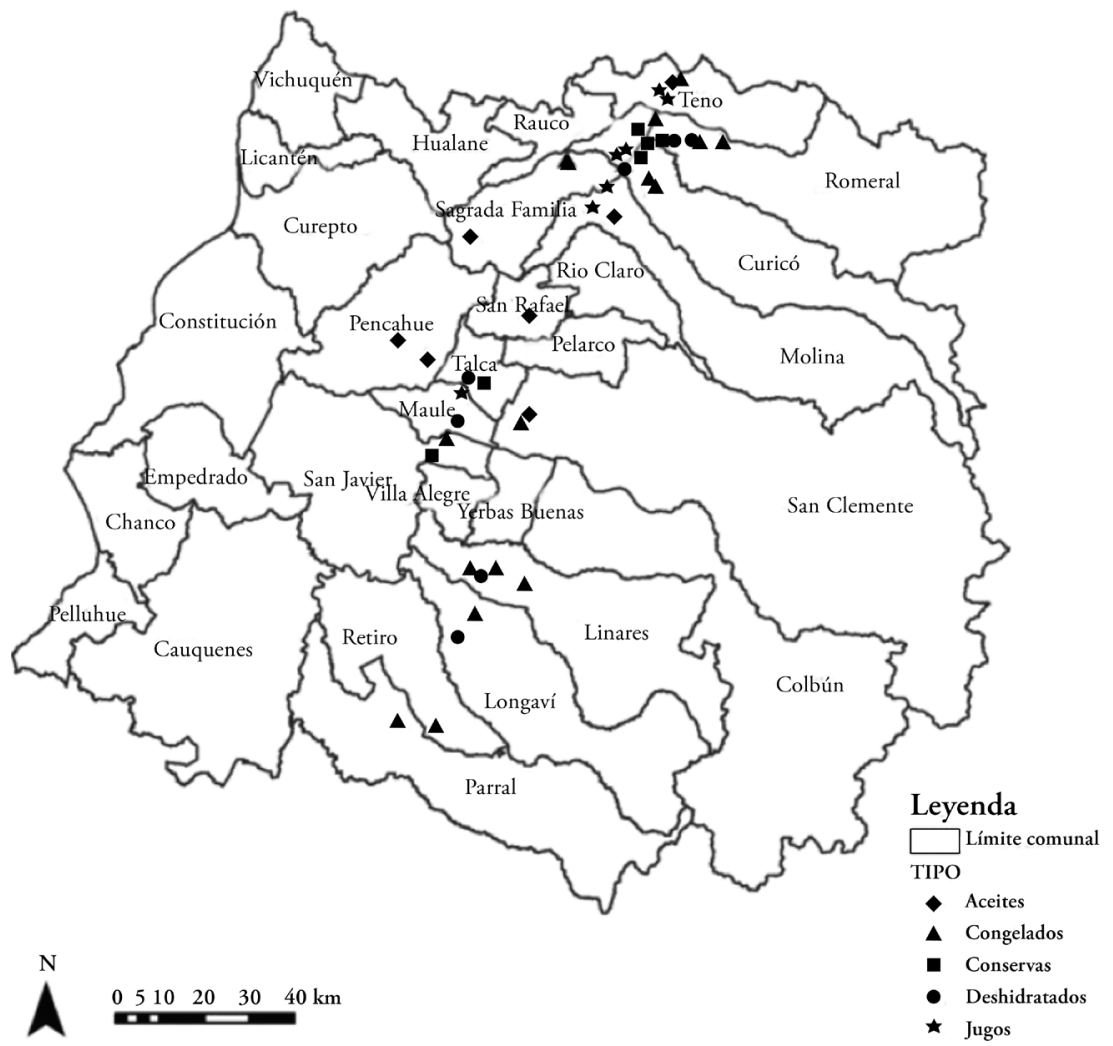

FUENTE ELABORACIÓN PROPIA A PARTIR DE INFORMACIÓN EN “ACTUALIZACIÓN DEL CATASTRO DE LA AGRoindustria HORTOFRUtícola CHILENA” (SANTIAgo, 2OI 2) 
Se observa una mayor concentración de cultivos frutícolas en la zona centro norte de la Región, situación que genera en estos territorios un mayor desarrollo de plantas agroindustriales asociadas al procesamiento de frutas (figura 2).

FIGURA 2 | Región del Maule: distribución de plantaciones frutales mayores por distrito agropecuario, 2007

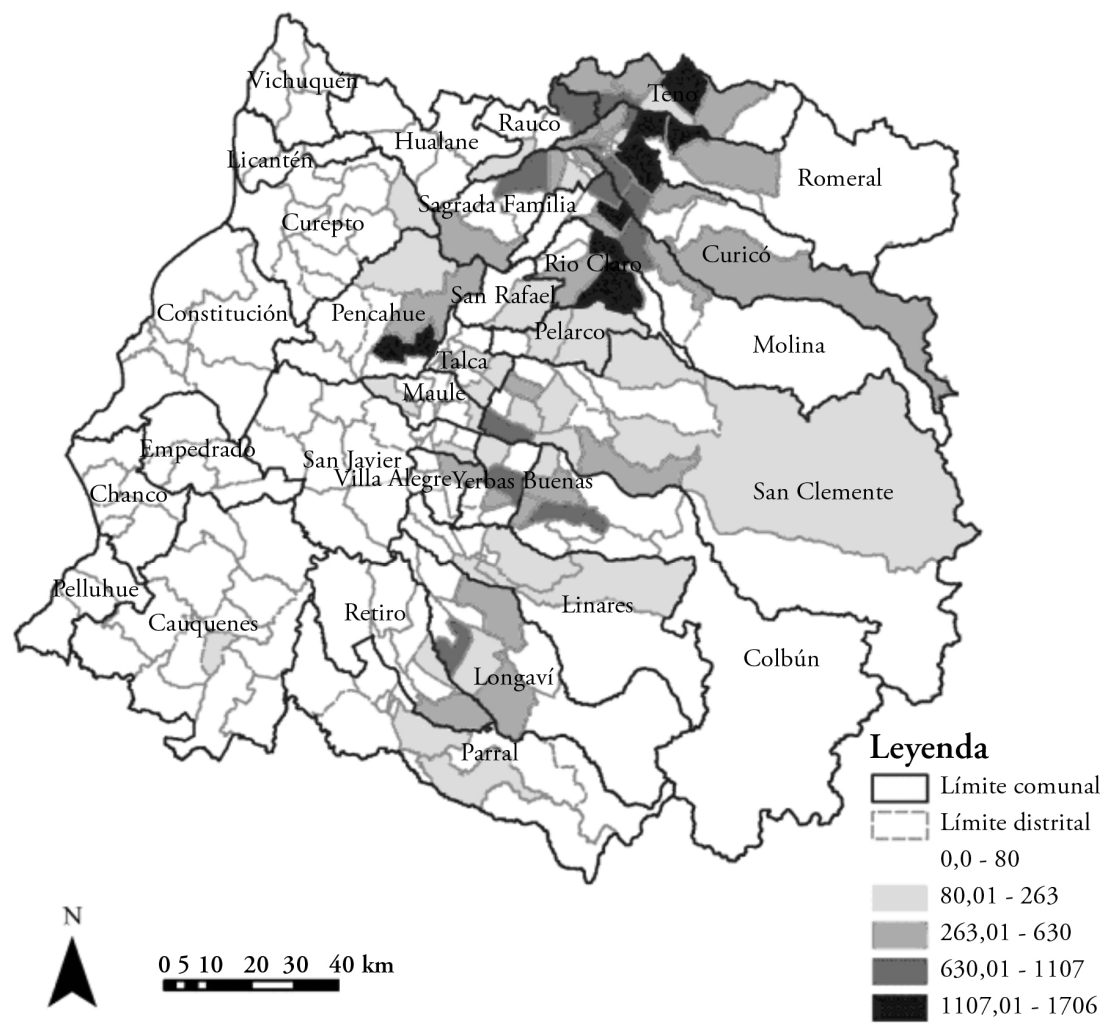

FUENTE ELABORACIÓN PROPIA A PARTIR DE INFORMACIÓN DEL CENSO AGROPECUARIO Y FORESTAL 2007 (INSTITUTO NACIONAL DE ESTADÍSTICAS, 2007)

Destaca la actividad silvícola, con mayor desarrollo en el secano interior y costero. Se asocia a la producción de celulosa y madera, que se industrializa en la comuna de Constitución (figura 3). Cabe señalar que fue en la segunda mitad de los años sesenta que se crearon las plantas Celulosa Arauco s.A. (1967) y Celulosa Constitución s.A. (1969), empresas Corfo (Corporación de Fomento de la Producción) privatizadas en 1977 y 1979 y luego fusionadas en Celulosa Arauco y Constitución s.A. 
FIGURA 3 | Región del Maule: distribución de la actividad silvícola, 2007

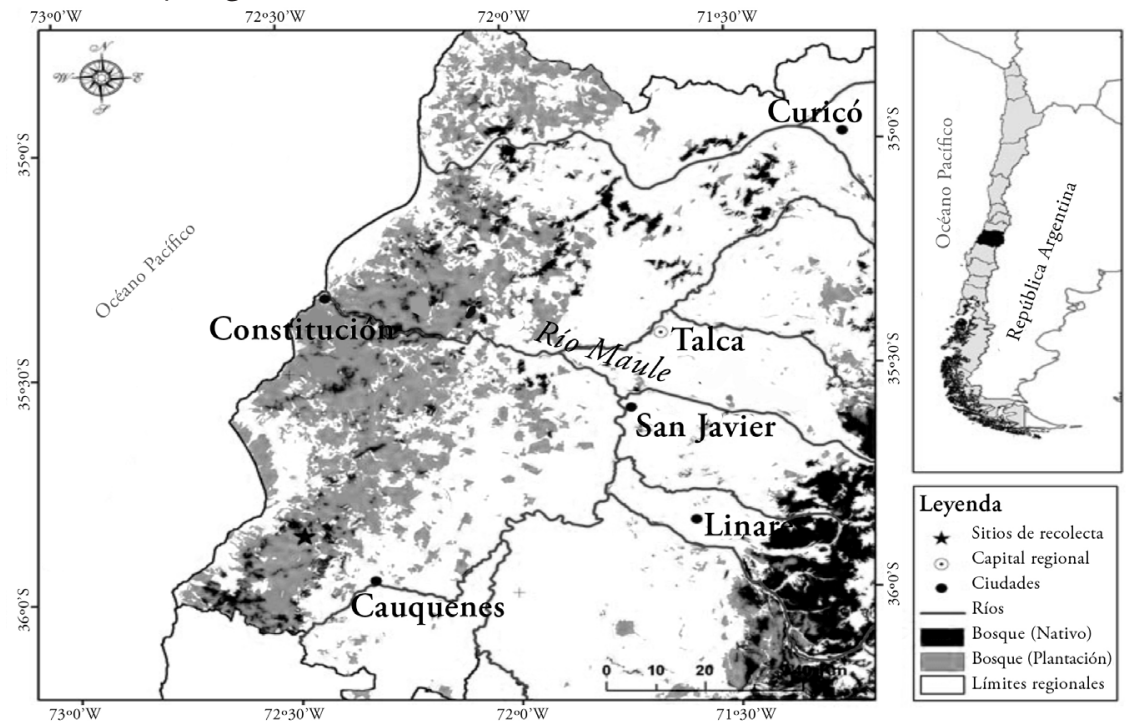

FUENTE ELABORACIÓN PROPIA A PARTIR DE INFORMACIÓN DEL CENSO AGROPECUARIO Y FORESTAL 2007 (INSTITUTO NACIONAL DE ESTADÍSTICAS, 2007)

Antes del proceso de regionalización, la comuna de Constitución pertenecía a la provincia del Maule, la que -de acuerdo con la propuesta conceptual de Paasi (2011) y Terlouw (2011) - consideraríamos como la "región antigua", conformada por los departamentos de Constitución, Cauquenes, Chanco y Pelluhue. Estos poseían más del $70 \%$ del litoral de la región y dos de las cinco principales ciudades; una de ellas, Constitución, la tercera en importancia económica en la actualidad. De este modo, Constitución pasó a formar parte de la provincia de Talca, y los restantes departamentos conformaron la nueva provincia de Cauquenes.

Las evidencias indican que los territorios con dinamismo productivo generaron sinergias con las ciudades principales, concentrando a la población, el mercado, la infraestructura, la representación, el poder político y la capacidad de gestión administrativa. Así, la regionalización, sustentada en un modelo exportador, facilitó un período de concentración inédito de la población en las provincias de Talca y Curicó, las cuales incrementaron su participación regional. Situación inversa experimentó la provincia de Cauquenes, y lo mismo ocurrió con Linares, aunque en menor medida.

El saldo migratorio para 1997-2010 (figura 4) muestra que las comunas del Maule que perdieron población se ubican en las zonas donde no se registra actividad agroindustrial. Las comunas de Talca y Curicó presentan los mayores saldos migratorios positivos, influenciadas por el tamaño y rol económico de sus ciudades cabeceras. 
CUADRo 1 | Evolución de la población según provincias, 1940-2012

\begin{tabular}{|c|c|c|c|c|c|c|c|c|}
\hline \multirow{2}{*}{ PROVINCIA } & \multicolumn{8}{|c|}{ CANTIDAD DE POBLACIÓN } \\
\hline & 1940 & 1952 & 1960 & 1970 & 1982 & 1992 & 2002 & 2012 \\
\hline Curicó & 81.185 & 89.432 & 105.802 & 114.654 & 188.017 & 220.647 & 244.053 & 272.752 \\
\hline Talca & 157.141 & 173.693 & 206.154 & 232.210 & 269.361 & 313.951 & 352.966 & 371.783 \\
\hline Maule/Cauquenes & 70.497 & 72.181 & 79.736 & 82.863 & 53.366 & 55.242 & 57.088 & 55.884 \\
\hline Linares & 134.968 & 146.257 & 171.350 & 189.403 & 219.843 & 246.201 & 253.990 & 267.916 \\
\hline Total & 443.791 & 481.563 & 563.042 & 619.130 & 730.587 & 836.041 & 908.097 & 968.335 \\
\hline \multirow{2}{*}{ PROVINCIA } & \multicolumn{8}{|c|}{ \% DE PARTICIPACIÓN EN LA POBLACIÓN REGIONAL } \\
\hline & I940 & 1952 & 1960 & 1970 & 1982 & 1992 & 2002 & 2012 \\
\hline Curicó & 18,3 & 18,6 & 18,8 & 18,5 & 25,7 & 26,4 & 26,9 & 28,2 \\
\hline Talca & 35,4 & 36,1 & 36,6 & 37,5 & 36,9 & 37,6 & 38,9 & 38,4 \\
\hline Maule/Cauquenes & 15,9 & 15,0 & 14,2 & 13,4 & 7,3 & 6,6 & 6,3 & 5,8 \\
\hline Linares & 30,4 & 30,4 & 30,4 & 30,6 & 30,1 & 29,4 & 28,0 & 27,7 \\
\hline
\end{tabular}

FUENTE ELABORACIÓN PROPIA A PARTIR DE LOS CENSOS DE POBLACIÓN Y VIVIENDA, AÑOS RESPECTIVOS

\section{FIGURA 4 | Región del Maule: saldo migratorio, 1997-2002}

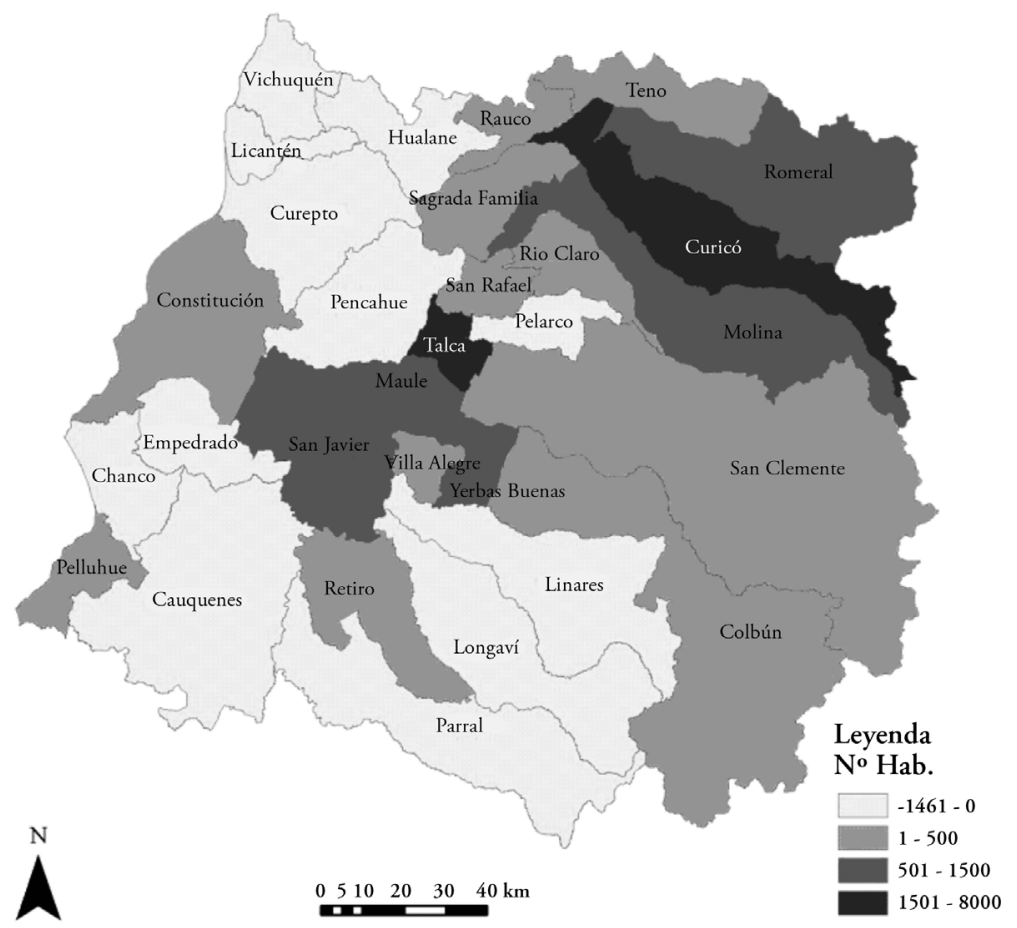

FUENTE ELABORACIÓN PROPIA A PARTIR DE INFORMACIÓN DEL CENSO DE POBLACIÓN Y VIVIENDA 2002 
Conjuntamente con la concentración del control político-administrativo, de la actividad productiva y de la población, se produce también una concentración en términos de servicios y equipamiento en las ciudades de Talca y Curicó (cuadro 2).

CUADro 2 | Región del Maule: servicios y equipamientos, por principales comunas

\begin{tabular}{|l|c|c|c|c|c|c|}
\hline \multirow{2}{*}{ COMUNA } & \multicolumn{7}{|c|}{ SERVICIOS } \\
\cline { 2 - 7 } & HOTELERÍA & RETAIL & SALUD & EDUCACIÓN & FINANCIEROS & $\begin{array}{c}\text { SUPER- } \\
\text { MERCADOS }\end{array}$ \\
\hline Cauquenes & 9 & 3 & 23 & 39 & 5 & 2 \\
\hline Constitución & 34 & 3 & 20 & 29 & 9 & 4 \\
\hline Curicó & 34 & 17 & 69 & 158 & 20 & 13 \\
\hline Linares & 21 & 12 & 41 & 92 & 13 & 8 \\
\hline Talca & 48 & 16 & 60 & 227 & 25 & 16 \\
\hline
\end{tabular}

FUENTE ELABORACIÓN PROPIA A PARTIR DE INFORMACIÓN CATASTRAL OBTENIDA EN EL MINISTERIO DEL INTERIOR

FIGURA 5 | Región del Maule: servicios de las principales comunas

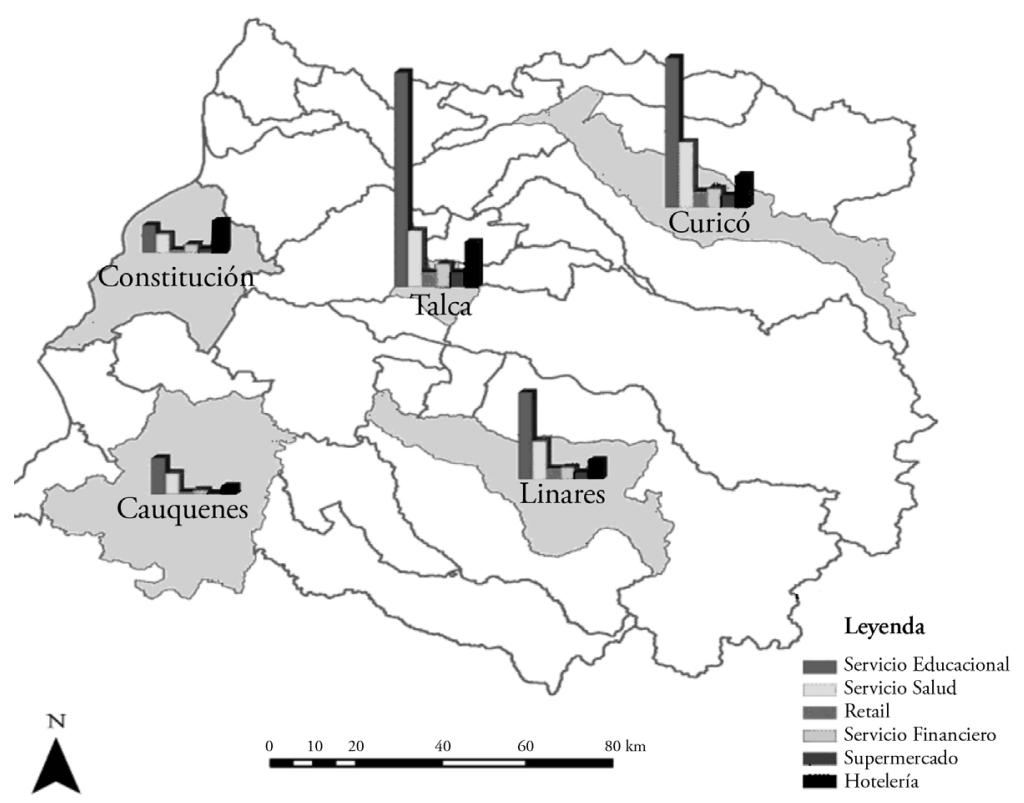

FUENTE ELABORACIÓN PROPIA A PARTIR DE INFORMACIÓN CATASTRAL OBTENIDA EN EL MINISTERIO DEL INTERIOR

Las transformaciones económicas de los últimos cuarenta años, sustentadas en la regionalización, han producido dualidad en el territorio, al instalar una región nueva, con mayor poder, más poblada, con mejores servicios y económicamente 
más activa. Como consecuencia, aquellas zonas que están fuera de la influencia de la región nueva tienen menor densidad de población, a la vez que menor dotación de servicios y dinamismo económico.

Definiremos la "región nueva" del Maule como un entramado institucional, con un aparato productivo establecido en ciudades y pueblos con actividades diversificadas y vinculadas al complejo agroexportador ${ }^{4}$. Dichos asentamientos son núcleos dinamizadores de las economías locales adyacentes, a través de la generación de empleos y servicios. Su área de influencia está constituida por la ciudad de Curicó, con sus comunas Sagrada Familia, Teno, Molina, Romeral; la ciudad de Talca, que abarca las comunas de San Clemente, San Javier, Maule; y el caso particular de la ciudad de Constitución, con una actividad económica desterritorializada, que se traduce en un bajo grado de influencia a comunas aledañas, como Empedrado y Curepto.

El resultado del nuevo esquema institucional es un incremento persistente en la concentración de la población y de la actividad económica en la región nueva. Bajo el criterio económico, las comunas que movilizan por concepto de ventas bajo los 4,5 millones de uf al año, serán tipificadas como parte de la región antigua; y como región nueva, las que movilizan más de esa cifra (cuadro 3).

CUADRo 3 | Maule, región nueva y región antigua, y sus comunas

\begin{tabular}{|l|l|}
\hline \multicolumn{2}{|c|}{ REGIóN NUEVA } \\
\hline Zona Talca & Talca, San Clemente, San Javier, Maule \\
\hline Zona Curicó & Curicó, Sagrada Familia, Teno, Molina, Romeral \\
\hline \multicolumn{2}{|c|}{ REGIóN ANTIGUA } \\
\hline Secano Interior & Parral, Hualañe, Cauquenes, Empedrado, Pencahue, Vichuquén, Licantén \\
\hline Secano Costa & Chanco, Pelluhue \\
\hline
\end{tabular}

FUENTE ELABORACIÓN PROPIA, CENTRO DE ESTUDIOS URBANO TERRITORIALES (CEUT), UNIVERSIDAD CATÓLICA DEL MAULE / CORPORACIÓN SURMAULE

La "región antigua” está compuesto por nueve comunas del secano y la costa, que forman una red de ciudades y pueblos vinculados a actividades piscisilvoagropecuarias, con un modelo productivo tradicional y actividad forestal desterritorializada, con escaso impacto en las dinámicas económicas de los territorios aledaños. Se caracterizan por una baja infraestructura y conectividad; alta dispersión poblacional e índices de ruralidad. Adicionalmente las localidades ubicadas en el Maule sur destacan por fuertes vínculos con el norte del Nuble, región del Biobío (San Carlos, Chillán, San Nicolás, San Fabián de Alico). Situación similar se da en el Maule norte, donde las redes son con Santa Cruz, San Fernando, Lolol, entre otros.

4 Definición basada en información del Servicio de Impuesto Internos (sII) sobre las ventas en UF realizadas en cada comuna el año 2012. A partir de esos datos, se creó una tipología que permite distinguir la antigua y nueva región. Véase página web del siı "Estadísticas de empresas por tamaño según ventas” (2005-2012), en http://www.sii.cl/estadisticas/empresas_tamano_ventas.htm 
$\mathrm{Al}$ analizar las zonas de influencia de Talca y Curicó, existe persistente concentración de población y actividad económica en la región nueva e inversamente proporcional en la región antigua. En la década de los cuarenta, existía equilibrio entre los pesos demográficos relativos de Talca y Curicó, sus zonas de influencia y la zona del secano interior y costero (cuadro 1). La región antigua, con diez comunas, representaba el 24,6\% de la población regional, más que las actuales zonas de influencia de Talca y Curicó, con 20,7\% y 23,1\%, respectivamente. En 1982, habiéndose iniciado el proceso de regionalización y el retiro de Constitución de la provincia de Maule, la participación de la región antigua en la población regional total caía a 13,1\%, mientras el “duopolio" Talca y Curicó llegaba a 31,1\%. En 2012 la situación se agudizó. La región antigua cayó a 10,1\%, Talca y Curicó alcanzaron un 35,2\%. Se añade que las zonas de influencia de estas ciudades, sumadas, representaban ese mismo ańo el $57,1 \%$ de la población, siendo solo diez comunas.

En términos de actividad económica, las nueve comunas de la región antigua representan un 3,9\% del total de las ventas de las empresas en la región, mientras que las nueve comunas de la región nueva llegan a 63,5\%.

CUADRo 4 Participación en la población regional y en las ventas de empresas de acuerdo a zonas

\begin{tabular}{|l|c|c|c|c|c|}
\hline \multirow{2}{*}{ ZONIFICACIONES } & \multicolumn{2}{|c|}{$\begin{array}{r}\text { \% DE LA } \\
\text { POBLACIÓN } \\
\text { RESPECTO DEL } \\
\text { TOTAL REGIONAL }\end{array}$} & $\begin{array}{c}\text { VENTAS DE LAS } \\
\text { EMPRESAS DEL } \\
\text { TERRITORIO } \\
\text { (UF) }\end{array}$ & $\begin{array}{c}\text { PARTICIPACIÓN } \\
\text { (\%) }\end{array}$ \\
\cline { 2 - 6 } & I940 & I982 & $\mathbf{2 0 I 2}$ & $\mathbf{2 0 I 2}$ & \\
\hline Talca y Curicó & 20,7 & 31,1 & 35,2 & 122.919 .742 & 44,9 \\
\hline Zona influencia Curicó (5) & 20,7 & 22,4 & 24,8 & 83.398 .080 & 30,5 \\
\hline Zona influencia Talca (4) & 23,1 & 30,5 & 32,3 & 90.465 .989 & 33,1 \\
\hline Total área Talca-Curicó & 43,8 & 52,9 & 57,1 & 173.864 .069 & 63,6 \\
\hline Secano + costa (incluyendo Constitución) & 24,6 & 17,4 & 14,4 & 56.643 .573 & 20,7 \\
\hline Secano + costa (excluyendo Constitución) & & 13,1 & 10,1 & 10.573 .862 & 3,9 \\
\hline Total ventas & & & $273.713 .211,6$ & 100 \\
\hline
\end{tabular}

UF: UNIDADES DE FOMENTO

FUENTE SERVICIO DE IMPUESTOS INTERNOS (SII VENTAS EN UF REALIZADAS EN CADA COMUNA EL AÑO 2OI 2. EN HTTP://WWW.SII.CL/ESTADISTICAS/EMPRESAS_TAMANO_VENTAS.HTM

Los espacios no conectados con la región nueva, que constituyen gran parte del territorio regional, en general están asociados a menor cobertura o provisión de servicios, pues allí estos tienen mayor costo, menor acceso a la información -vital en tiempos de globalización- y mayor dificultad para atraer factores de producción; por tanto, menor acceso a la infraestructura productiva. Asimismo, las administraciones locales muestran sistemáticamente la imposibilidad de cubrir estas amplias zonas geográficas, lo que decanta en la antesala de la decadencia de su espacio (Arenas, 1999). 
Los procesos de concentración espacial, que están ligados a la distribución de los recursos en el territorio, apuntan al mercado como el agente de mayor incidencia en tal situación. Así, la aglomeración o concentración de actividades económicas refleja procesos de causación acumulativas: "Las actividades se agrupan donde los mercados son grandes y los mercados se vuelven grandes donde las actividades se agrupan” (Krugman, 1997, p. 56). Incluso estos procesos, que se manifiestan en ambientes típicamente urbanos, hoy están dirigidos a todas las actividades económicas, no solamente a los sectores productivos (Camagni, 2005). Y ello significa la discriminación o selección de espacios según sus formas de integración económica, las cuales determinan que algunos espacios sean dinámicos y otros se mantengan en situación de subutilización o simplemente de abandono (Arenas \& Sabatini, 1994).

\section{Representaciones sociales de la nueva y antigua región en el Maule}

En el ámbito de las representaciones del territorio, se advierte una fuerte identificación con la matriz rural. Se reconoce que esta zona del país tiene una base ligada a la producción agraria que permea las dinámicas socioculturales de sus habitantes, expresándose en relaciones sociales, formas de habitar, creencias, costumbres, cultura y patrimonio, entre otros.

En la región del Maule existe un mundo que se identifica más profundamente con ser maulino... Es imposible no ver esta realidad cultural, que tiene que ver con lo religioso, con la tierra, con las formas tradicionales de habitar... (elite políticainstitucional).

Para algunos, ser considerado como "campesino" o "huaso" tiene una connotación favorable, porque reconocen ciertos rasgos positivos en esa denominación. Para otros, en cambio, los términos "huaso" o "campesino" connotan una abierta discriminación, principalmente porque perciben la existencia de una profunda desvalorización del modo de vida rural. Simbólicamente opera la distinción campo-ciudad, la que se extiende a otras más generales, como tradicional-moderno, competitivo-no competitivo, atrasado-avanzado, centro-periferia.

No es una imagen muy positiva [la de ruralidad]... Es la imagen de una región que está en el medio de cosas importantes, pero que en sí no es muy importante, que no tiene muchos servicios, que está atrasada. Lo rural de esta región la hace

\footnotetext{
La teoría de la causación acumulativa, de Gunnar Myrdal, considera que "el crecimiento regional es un proceso desequilibrado, y prevé que una mayor dinámica surgida en una de las regiones no impulsa la de las colindantes, sino su mayor empobrecimiento relativo. Plantea que las regiones que presentan ventajas iniciales experimentan en forma sostenida un mayor crecimiento, favorecido por la acumulación industrial y el desarrollo de la infraestructura, que en conjunto generan importantes economías internas y externas y explican el aumento en las disparidades y presencia de un flujo neto de recursos productivos hacia ellas". Véase M. A. Gaviria, Apuntes de economía regional (Pereira, Colombia: Universidad Católica Popular de Risaralda, 2010), p.15. Disponible en http://www.eumed.net/libros-gratis/2010f/873/teoria $\% 20 \mathrm{de} \% 20 \mathrm{la} \% 20$ causacion\%20acumulativa.htm
} 
ser más atrasada; lo rural es lo atrasado y lo urbano, lo moderno (elite políticainstitucional).

Esta situación se agudiza en aquellos sujetos que habitan la antigua región, poco integrada al desarrollo agroindustrial, con pérdida de población debido a la atracción que ejercen el pueblo o la ciudad, dada su oferta de servicios básicos y trabajo. Los que se quedan justifican su decisión en función de elementos socioculturales e identitarios, el sentido de pertenencia al lugar y sus formas de vida, y el "ganarse la vida”.

Toda la gente se va pa' Linares. Soy el único que está quedando aquí... No quiero terminar esto aquí, por el recuerdo de mi padre. No me acostumbro a vivir en Linares, no me gusta; me llevan a pasear, no me acostumbro... Aquí en El Bajo, se ha ido gente mucha... Se van pa' buscar comodidad en la ciudad, a buscar trabajo en la fruta, parronales, creo...

No se me ha ocurrido na', oiga, irme [se ríe junto a su hermana]... Cuando nos cabriemos de hacer carbón, nos iremos; si este trabajo es bien pesado, oiga... hacer leña y carbón es pesado... Además no es na’ llegar e irse; es complicado, porque hay que acostumbrarse y hay que tener un trabajo... de qué va a vivir uno... (carbonero de la localidad El Culmen, provincia de Linares).

El desarrollo dual de los territorios se explica por la coexistencia de una agricultura moderna y otra tradicional; la moderna es representada por empresas nacionales -incluso trasnacionales- altamente tecnologizadas y competitivas, abiertas al mercado externo, ubicadas principalmente en la nueva región; y la tradicional, empresas locales y regionales, menos tecnologizadas y competitivas, dirigidas al mercado interno, con serias dificultades de vinculación y encadenamiento productivo. Las primeras concentran la actividad económica agroindustrial que en las últimas décadas ha transformado los territorios, sus usos productivos, el mercado laboral, el paisaje y los estilos de vida. La nueva región es percibida por sus habitantes como aquella que ofrece mayores y mejores oportunidades y acceso a servicios, mayor conectividad y participación femenina en las labores agrícolas, entre otras ventajas.

Aquí la cuestión de la fruta se hizo más fuerte, hay mucho trabajo; llegando octubre empieza la gente a venir a trabajar, en el tiempo de las cerezas, las frambuesas, las frutillas. Hay trabajo hasta pasado mayo. A mediados de junio, ahí Romeral se estanca. La vida en Romeral, cuando empieza el tiempo de las cosechas, es buena; toda la gente gana plata, todos los niños ganan plata, la juventud, todo el mundo gana y las mujeres salen todas a trabajar. Hay mucha gente que prefiere trabajar de temporera que estar establecidos. Claro, porque ellos ganan, por ejemplo, lo que uno gana en el año, ellos lo ganan en cuatro, cinco meses (hombre, folclorista, 70 ańos, comuna de Romeral).

Para los habitantes de la antigua región, la percepción del territorio no es favorable. Ven la actividad agrícola tradicional en decadencia, situación a la que se suma la expansión de la actividad forestal, que lejos de mejorar las condiciones de vida, ha 
gatillado procesos migratorios por la falta de oportunidades laborales y el cambio del ecosistema.

Este era un pueblo netamente agricultor, donde se producía el trigo, las legumbres, el vino, prácticamente. Nirivilo era un sector rural donde se preocupaban de las siembras, de las cosechas, las trillas, las vendimias. Donde antes el medio de transporte eran caballos y carretas...Pero ahora todo eso se ha perdido. Lo único que queda son los pinos, ahora más que nada lo que hay es el pino. Si hasta el paisaje cambió. Uno mira para los cerros, pinos; mira para "El Bajo", pinos... (mujer, catequista de la localidad de Nirivilo, comuna de San Javier).

La reconfiguración del territorio en la década de los setenta, producto de la división político-administrativa, potenció la actividad silvoagropecuaria generando dinámicas territoriales diversas. Para el caso de la agroindustria, esta encontró su espacio de desarrollo en el Valle Central, aumentando la densidad poblacional, la concentración de servicios y del poder en la urbe. Para el caso de la industria forestal, ubicada en la zona del secano, su desarrollo es percibido como desterritorializado.

La verdad es que nosotros utilizamos términos bien vulgares, decimos: "Constitución es como el patio trasero de la región del Maule”... o sea, se considera Constitución como indicador económico, por la producción de madera, de celulosa, por lo que aporta al producto interno, pero ¿cuánto de lo que se produce queda para sus habitantes...? (mundo del trabajo).

Un 77,7\% de los habitantes del Maule señala que el lugar donde suceden las "cosas importantes" es la capital regional (Talca) y un 52,4\% de los entrevistados declara querer vivir en las ciudades capitales de la región: Talca, Curicó y Linares (Gobierno Regional del Maule, 2011). Al contrario, el secano se percibe como un territorio que ha perdido poder político, económico e importancia demográfica. Existe en el recuerdo de los sujetos del secano una dinámica productiva potente vinculada al proceso de comercialización y exportación de granos, la que empezó a debilitarse en la década de los sesenta con la instalación del complejo forestal. Las representaciones sociales que construye el colectivo sobre la región aluden básicamente a un cambio en las dinámicas productivas, con el consiguiente traslado del poder económico.

Había inmensas bodegas y maquinarias de donde se seleccionaba la lenteja, balanza donde se empaquetaban y pesaban, y, bueno, esta lenteja se iba a Talcahuano y de allí se exportaron, de ahí se iba fuera del país. El año 66 empezó la caída de la producción de lenteja y la comercialización, bajó lo que era la producción de lenteja y aumentó lo que era lo forestal. Entonces toda la gente empezó a trabajar en las forestales plantando árboles y otros cortando árboles, trabajando en lo forestal (hombre, agricultor, comuna de Chanco).

El tipo de desarrollo señalado provoca disparidad entre territorios y genera sentimientos de competencia, donde destacan las pugnas entre provincias y comunas. Las personas perciben sus lugares de pertenencia en desventaja frente a otros; los del sur miran hacia al norte y los del norte hacia el sur. Surge el cuestionamiento frente al origen de la región como puro hecho administrativo. Pareciera no haber 
una valoración del lugar: las cosas no suceden ahí, pasan en otras partes. Existe un espacio de confrontación o competencia entre Maule sur y Maule norte, provincias y ciudades, que impiden la construcción de un proyecto regional.

Viviendo en la parte centro de la región, comparo todos los adelantos que se ven en la zona norte de la región. Creo que Talca se ve muy favorecida con todas las políticas regionales, y en desventaja veo mucho a Linares y Cauquenes... Ahí ya no tocan nada, porque se ve una ciudad totalmente muerta, apagada, sin vida, sin progreso. En Linares, desde hace veinte ańos atrás no se ve ningún progreso; en la parte comercial, se ve totalmente muerto Linares en relación a Talca, que es una ciudad totalmente viva; todo llega a Talca, lo más moderno. Es una gran desventaja que aunque los políticos luchan, alegan, están favoreciendo mucho a la Séptima Norte y dejando de lado la Séptima Sur. No se están preocupando de Linares, Parral, Cauquenes; están favoreciendo mucho... incluso Curicó ha despertado bastante en el último tiempo (mujer, profesora rural, comuna de San Javier).

La nueva región es percibida con una mayor oferta de oportunidades en educación, salud, protección social; también en el mercado, especialmente la oferta de trabajo; y en cuanto a la sociedad civil, se perciben en la nueva región ventajas en materia de redes y organizaciones sociales, todo lo cual deja en situación de desventaja a la antigua región.

En la zona hay poco trabajo, llamémoslo así, tanto empresarial, aunque sean pequeñas empresas, como intelectual. Incluso la gente cree que el destino es trabajar en la Municipalidad, y esta no puede absorber a todo el mundo; incluso en la Municipalidad, hay más gente de la necesaria. Cada alcalde va trayendo gente y el problema es que hay veces que no hay mayor destino. Es muy malo, porque los jóvenes no vuelven o vuelven de viejos. La parte laboral es muy débil, muy débil (hombre, profesional, comuna de Vichuquén).

La nueva región ha quedado desanclada de la identidad de la antigua región, lo que mina la constitución de ambas como un todo. La región del Maule es un espacio político-administrativo que no ha logrado instituirse como una realidad sociocultural. Aparece como un territorio fragmentado, caracterizado por distancias, rivalidades y pugnas internas. Las dinámicas económicas concentradoras han tendido a generar territorios "ganadores" y territorios "perdedores", ante lo cual se percibe que el Estado no ha tenido un rol de regulación relevante. La distancia entre la región político-administrativa y los territorios socioculturales genera un malestar simbólico en los sujetos, que no se sienten representados por el "Estado Regional". Se observa que esta forma de representación de los territorios -económica y administrativa- invisibiliza el tejido social, vaciando de contenido cualitativo a los procesos que dinamizan la región. De ahí que solo se reconozca la existencia de estos territorios por su aporte al PIB regional y no por su riqueza sociocultural o como portadores de capital social.

Pero pese al desajuste entre la región nueva y la antigua, y al notable debilitamiento de la capacidad de esta última de definir un proyecto de desarrollo propio, existen importantes señales que dan cuenta de un hibridaje entre lo nuevo y lo 
antiguo. Una de las dimensiones donde se observa esta "ambigüedad" es en las relaciones urbano-rurales. En términos culturales, se constata una alta adscripción al "ser rural" en ciudades como Talca y Curicó (las zonas más urbanas de la región y que hemos definido como los centros de comando de la región nueva). Cuando se les pregunta a los habitantes de Talca si se sienten urbanos o rurales, un $45 \%$ dice sentirse rural o un poco rural. En Curicó y Linares este porcentaje sube a 54\% y en núcleos urbanos de más de 15.000 habitantes llega a 64\% (Centro de Estudios Urbano Territoriales [CEUT], 2014). Si bien falta por conocer el contenido de estas adscripciones, lo cierto es que si seguimos las definiciones dicotómicas de lo rural y lo urbano, y reconocemos el proceso de constitución de la región nueva como uno de modernización (González, 2013), resulta paradójico que muchos de quienes habitan sus locus de control se sientan perteneciente, al menos en parte, a una identidad más bien asociada a la región antigua. También en términos culturales relevamos un amplio conjunto de prácticas rurales en las ciudades. Se trataría de un proceso de interpenetración de los contrarios (Galimberti, 2011, p. 7), que en la urbe se desarrolla en la medida en que "otros modos, estilos y lógicas de reproducción no siguen los parámetros de la razón dominante y se encarnan en los actores rurales que viven y/o trabajan en la ciudad" (Kenbel \& Cimadevilla, 2009, p. 8).

Además, observamos el hibridaje a nivel económico. Así, en la región antigua existe un creciente desarrollo de actividades productivas que combinan la matriz agroexportadora con el turismo de intereses especiales, y en algunos casos con la producción de innovaciones biogenéticas, como ocurre en la actividad vitivinícola. A manera de contraparte, en la región nueva persisten enclaves de agricultura familiar campesina, expresión de un modo "no moderno" de producción agrícola.

\section{Discusión}

La idea subyacente de este artículo es que, en la región del Maule, la realidad político-administrativa, en alianza con el mercado, ha sido protagonista del desarrollo regional durante los últimos cuarenta años. Esta percepción es coherente con el hecho que -según dijimos- las nuevas regiones son típicamente construidas ad hoc para proyectos que aspiran a desarrollar la competitividad. No son los actores locales y los territorios los que han configurado el proyecto regional, sino que, más bien, un determinado proyecto nacional-regional les ha sido impuesto.

Dado lo anterior, la distancia entre lo local y lo regional parece abismante, frente a lo cual la posibilidad que queda es que cada territorio intente resguardar, dentro de sus posibilidades, sus propios intereses. En la medida en que la región no se constituya como realidad simbólica -o, al menos, en la medida en que no propicie mejores maneras de representar políticamente lo territorial y local-, la adhesión a la región 
como realidad cultural no será viable. Un proyecto de desarrollo regional no debería imponerse desde la jerarquía administrativa de la región, sino que debería explorar aquellos "grupos de estatus", según los denomina Weber. Y, de esta forma, contribuir a fortalecer aquellos mecanismos de articulación entre esos grupos, poniendo en juego la influencia, la compensación y el compromiso entre ellos. Solo así la región estará en condiciones de asegurar su desarrollo mediante la consolidación de su identidad y, a la vez, respetando las diversidades existentes (Amtmann, 1997).

Como indica Boisier (2000), en Chile las regiones administrativas son una entelequia creada artificialmente, por lo que carecen de un elemento aglutinador cultural capaz de producir una autorreferencia e identificación socioterritorial. Este es un problema relevante en el caso de las regiones multiprovinciales, en las cuales existen diversas manifestaciones culturales de orden local, sin que lleguen a plasmar una verdadera cultura de la región. Esto ha llevado a sostener que todo proyecto colectivo de desarrollo (todo proyecto político regional) debe entrelazarse con un proyecto cultural paralelo, capaz de crear la cultura de la región (Boisier, 2000, p. 101).

Terlouw (2011) advierte que las identidades regionales antiguas profundas, con fuertes raíces históricas, y las nuevas y superficiales, las cuales son más basadas en redes, fluidas, orientadas al futuro, no son opuestas, sino solo una herramienta conceptual. Las administraciones regionales recurren para su actuar a ambas formas de identidad. Ejemplo de aquello es que, para estimular el desarrollo económico, ponen el acento en las identidades superficiales, y los aspectos profundos de la identidad regional son usados para potenciar el capital social. Aunque las superficiales están generalmente en aumento, la relación con aspectos de las profundas es importante para legitimar políticas orientadas a la competitividad. Una mezcla entre ambas parece ser el mejor camino (Terlouw, 2011).

Se constata en la práctica que los criterios utilizados por el Estado para configurar lo regional, y actuar en ese nivel, requieren ser revisados, para incorporar en ellos la multidimensionalidad de la dinámica del territorio en tanto construcción social que resulta de aquella actividad espacial que es expresión de la desigual distribución del poder, la fragmentación, el conflicto e hibridaje. Si lo regional sigue concebido desde arriba, carecerá de la densidad de sentidos y pertenencia que genera la antigua región.

Existen perspectivas de desarrollo que pueden orientar estos procesos de articulación entre la región antigua y la nueva, o entre lo regional y lo local: desarrollo territorial, desarrollo local, etnodesarrollo, desarrollo endógeno, entre otras (González, 2013). Todas pueden constituirse en interesantes horizontes normativos para articular lo nuevo y lo viejo, aprovechando los escenarios que pone la globalización para la revalorización del territorio. Sin embargo, en países centralistas como el nuestro, es necesario partir por un proceso sostenido de visibilización y fortalecimiento de

6 Para Weber, los "grupos de estatus", a diferencias de las clases sociales, "se distinguen por su modo de consumo y por sus prácticas sociales diferenciadas que dependen a la vez de elementos objetivos (nacimiento, profesión, nivel educativo) y de otros puramente subjetivos (consideración, reputación...). Estos 'grupos de estatus' se distinguen unos de otros por estilos o 'modos de vida' (concepto que hay que comprender por oposición a 'nivel de vida')”. Véase R. Alcoberro, "Introducción a Max Weber (1864-1920)". En http://www.alcoberro.info/V1/weber.htm 
lo local. El rol de las políticas públicas en la construcción de una ciudadanía a nivel local implica asumir la acción pública a nivel regional, poniéndose al servicio de la representación del territorio, por sobre su "control".

La construcción de lo regional no se resuelve en la díada región / país, sino en la tensión regional / local. Esto significa que no habrá región real mientras no se reconozca el complejo mosaico de espacios locales y lo local sienta la necesidad de vincularse con algo mayor que sí mismo, la región.

\section{Referencias bibliográficas}

Actualización del catastro de la agroindustria hortofrutícola chilena. Informe final. Elaborado por Innovación para el Desarrollo Agrario Consultora Ltda. Estudio contratado por la Subsecretaría de Agricultura, Santiago, marzo de 2012. En http://www.odepa.gob.cl/ odepaweb/servicios-informacion/publica/Catastro_Agroindustrial_Informe_final.pdf

Allen, J., Massey, A. \& Cochrane, A. (1998). Rethinking the Region. Londres / Nueva York: Routledge.

Altman, D. (2011). Elección directa de consejeros regionales: ¡remedio o placebo? Apuntes Legislativos, (13). Santiago: Centro de Políticas Públicas, P. Universidad Católica de Chile. En http://politicaspublicas.uc.cl/publicaciones/ver_publicacion/9

Amtmann, C. (1997). Identidad regional y articulación de los actores sociales. Procesos de desarrollo regional. Revista Austral de Ciencias Sociales, (1), 5-14. En http:// mingaonline.uach.cl/pdf/racs/n1/art01.pdf

Arenas, F. (1999). Organización territorial y desarrollo regional en Chile. Estudios Geográficos, 60(234), 101-119.

Arenas, F., Hidalgo, R., Orellana, A. \& Aliaga, G. (2007). Propuesta de nuevos criterios para definir unidades políticos-administrativas regionales en Chile. En Camino al Bicentenario. Propuestas para Chile [Concurso Políticas Públicas 2007] (pp. 349374). Santiago: Gobierno de Chile / P. Universidad Católica de Chile. En http://bit. ly/1nUOWfM

Arenas, F. \& Sabatini, F. (1994). Comunidades territoriales pobres y explotación de recursos naturales. Ambiente y Desarrollo, 10(3), 36-42. En http://www.cipma.cl/ web/200.75.6.169/RAD/1994/3_Arenas_Sabattini_II.pdf

Banchs, M. (2000). Aproximaciones procesuales y estructurales al estudio de las representaciones sociales. Papers on Social Representations, 9(3), 1-15. En http://www.psych.lse.ac.uk/ psr/PSR2000/9_3Banch.pdf

Barómetro Regional 2013. Una mirada comparada a tres regiones diferentes: Biobio, Los Ríos y Los Lagos. Centro de Investigación Sociedad y Políticas Públicas, Universidad de Los Lagos. Disponible en http://www.academia.edu/4414081/Barometro_Regional_2013_

Bengoa, J. (2008). Valle Central: imaginarios, interpretaciones, ensoñaciones. Revista de la Escuela de Arquitectura de la Universidad de Talca. (2), 18-25. Disponible en http:// www.revistatalca.cl/revistas/Revista_TALCA_02.pdf

Boisier, S. (1998). Post-scriptum sobre desarrollo regional. Modelos reales y modelos mentales. EURE, 24(72), 53-69. http://dx.doi.org/10.4067/S0250-71611998007200003 
Boisier, S. (2000). Chile: la vocación regionalista del gobierno militar. EURE, 26(77), 81-107. http://dx.doi.org/10.4067/S0250-71612000007700004

Camagni, R. (2005). Economia urbana. Barcelona: Antoni Bosch editor.

Centro de Estudios Urbano Territoriales (CEUT) (2014). Encuesta regional de caracterización regional. (No publicada).

Cuervo, L. (2006). Globalización y territorio. Serie Gestión Pública, 56. Santiago: Instituto Latinoamericano y del Caribe de Planificación Económica y Social (ILPES), Comisión Económica para América Latina y el Caribe (CEPAL). En http://www.cepal.org/ publicaciones/Ilpes/8/LCIPL2508P/sgp56.PDF

Deas, I. \& Lord, A. (2006), From new regionalism to an unusual regionalism? The emergence of non-standard regional spaces and lessons for the territorial reorganization of the State. Urban Studies, 43(10), 1847-1877. doi: 10.1080/00420980600838143

Encuesta Nacional de Estratificación Social (enes) (2009). Proyecto Desigualdades. Tendencias y procesos emergentes en la estratificación social (Proyecto Anillos SOC12-CONICYT). En http:// www.desigualdades.cl/

Espinoza, V. \& Rabi-Blondel, V. (2013). La gobernanza del desarrollo regional: Analizando la toma de decisiones para la inversión pública regional en Chile. [Documento de trabajo del proyecto Fondecyt No 1120846: Incidencia de las redes políticas en decisiones de desarrollo regional]. Ponencia presentada en el primer Conversatorio Regional en Coquimbo, sobre El fomento productivo regional: ¿clíster o emprendedores?, realizado en La Serena, el 3 de septiembre de 2013. En http://actacientifica.servicioit.cl/biblioteca/ gt/GT13/GT13_Espinoza_RabiBlondel.pdf

Franco, M. C., Flórez, A., Montañez, G., Rodríguez de Moreno, A. \& Torres de Cárdenas, R. (1997). Geografía y ambiente. Enfoques y perspectivas. Santafé de Bogotá: Ediciones Universidad de la Sabana. En http://educacionyeducadores.unisabana.edu.co/index. php/eye/article/view/472/610

Galimberti, S. (2011). Rurbanidad, objetos y significaciones. Un estudio acerca de los actores rurbanos y la política pública. En: XXXIV Congresso Brasileiro de Ciências da Comunicação, Recife, Brasil.

García, C. (2006). Las representaciones sociales del territorio. Enfoque y metodología para su estudio. Controversia, (186), 78-87. En http://bit.ly/1ufyoZb

García-Huidobro, A \& Maragaño, A. (2010). La vertebración territorial en regiones de alta especialización: Valle Central de Chile. Alcances para el desarrollo de zonas rezagadas en torno a los recursos naturales. EURE, 36(107), 49-65. http://dx.doi.org/10.4067/ S0250-71612010000100003

Giddens, A. (1984). Constitución de la sociedad. Buenos Aires: Amorrortu.

Giménez, G. (1994). Apuntes para una teoría de la región y de la identidad regional. Estudios sobre las culturas contemporáneas, 6(18), 165-173. En http://www.redalyc.org/articulo. oa?id=31661809

Gobierno Regional del Maule (2011). Identidad e identidades del Maule. Claves para imaginar el desarrollo regional. Coordinación, investigación y textos: C. Concha Saldías \& F. Letelier Troncoso. Talca: Universidad Católica del Maule / Centro de Estudios surmaule. En http://www.surmaule.cl/wp-content/uploads/2013/07/identidadesmaule.pdf 
González, R. (2013). Revisitando la historia de las teorías del desarrollo. CUHS. Cultura Hombre - Sociedad, 23(1), 55-91. Disponible en http://cuhso.cl/index.php/cuhso/ article/view/386

Instituto Nacional de Estadísticas (INE), Chile (2007). VII Censo Agropecuario y Forestal 2007. Santiago: Autor. Disponible en http://www.ine.cl/canales/chile_estadistico/censos_ agropecuarios/censo_agropecuario_07.php

Jodelet, D. (1986). La representación social: fenómenos, concepto y teoría. En S. Moscovici (Ed.), Psicología social II. Pensamiento y vida social. Psicología social y problemas sociales (pp. 469- 494). Barcelona: Paidós.

Kenbel, C. \& Cimadevilla, G. (2009). La rurbanidad desde el enfoque de las memorias sociales. En X Jornadas Argentinas de Estudios de Población, 2009, San Fernando del Valle de Catamarca, Argentina.

Krugman, P. (1997). La organización espontánea de la economia: The self-organizing economy. Barcelona: Antoni Bosch editor.

Méndez, M. L. (2007). Propuesta conceptual del Programa de Identidad Regional: "el ámbito sociocultural como eje vertebral para el desarrollo regional: el concepto de identidad regional que queremos". Disponible en http://www.subdere.gov.cl/1510/article-72848.html [Consultado 10-05-2009; actualmente no vigente].

Mertins, G. (2000). Ciudades medianas en América Latina: criterios, indicadores y el intento de un modelo de su diferenciación socioespacial y funcional. Espacio y Desarrollo, (12), 123-140. Disponible en http://revistas.pucp.edu.pe/index.php/espacioydesarrollo/ article/view/8081

Montañez, G. \& Delgado, O. (1998). Espacio, territorio y región: conceptos básicos para un proyecto nacional. Cuadernos de Geografia, 7(1-2), 121-134. Disponible en http:// www.insumisos.com/lecturasinsumisas/Espacio_territorio\%20y\%20region.pdf

Moscovici, S. (Comp.) (1985). Psicología social II. Pensamiento y vida social. Psicología social y problemas sociales. Barcelona: Paidós.

Paasi, A. (2011). The region, identity, and power. Procedia - Social and Behavioral Science, 14, 9-16. doi: 10.1016/j.sbspro.2011.03.011

Programa de Naciones Unidas para el Desarrollo (PNUD) (2000). Desarrollo bumano en Chile 2000: Más sociedad para gobernar el futuro. Informe elaborado por E. Ortega, P. Güell, N. Lechner \& R. Vásquez. Santiago: Autor. Disponible en http:// repositoriodigitalonemi.cl/web/handle/2012/777

Romero, H., Toledo, X. \& Órdenes, F. (2001). Ecología urbana y gestión ambiental sustentable de las ciudades intermedias chilenas. Ambiente y Desarrollo, 17(4), 45-51. Disponible en http://www.cipma.cl/web/200.75.6.169/RAD/2001/4_Romero.pdf

Rovira, A. (2000). Puerto Montt: el paso de una ciudad menor a centro de desarrollo interregional en una ciudad del sur de Chile. Espacio y Desarrollo, (12), 83-102. Disponible en http://revistas.pucp.edu.pe/index.php/espacioydesarrollo/article/view/8090/8385

Santos, M. (1997). Técnica, espaço, tempo. Globalização e meio técnico-cientifico social informacional. São Paulo: Editora Hucitec.

Shelby, T. (2005). Who are dark: The philosophical foundations of black solidarity. Cambridge, MA: Harvard University Press.

Soja, E. (1989). Postmodern Geographies. The reassertion of space in critical social theory. Londres: Verso/New Left Books. 
Subsecretaría de Desarrollo Regional (Subdere), Chile (2009). Antecedentes del barómetro regional. Santiago: Autor.

Subsecretaría de Desarrollo Regional (Subdere), Chile (2010). Masa crítica de condiciones para el desarrollo de las regiones en Chile. Antecedentes para una discusión incipiente. Santiago: Autor. En http://www.subdere.gov.cl/sites/default/files/documentos/articles-83100_ archivo_fuente_0.pdf

Terlouw, K. (2011). From thick to thin regional identities? GeoJournal, 77(5), 707-721. doi: $10.1007 / \mathrm{s} 10708-011-9422-\mathrm{x}$

Universidad de Los Lagos (2010). Informe final. Estudio Articulación y actores para la descentralización en tres regiones de Chile (ID761-108-LP08). Programa Ciudadanía y Gestión Pública, Universidad de Los Lagos, Sede Santiago. Santiago de Chile, marzo 2010. Disponible en http://www.innovacionciudadana.cl/portal/imagen/File/ descentralizacion/INFORME\%20FINAL.pdf

Valenzuela, E. (1999). Alegato histórico regionalista. Santiago: Ediciones SUR. 